\title{
Analysis of seismic attributes to enhance Bottom Simulating Reflectors in the gas hydrate field, Umitaka Spur, eastern margin of Japan Sea
}

Eloíse Helena Policarpo Neves ${ }^{* 1}$, Antonio Fernando Menezes Freire1, Cleverson Guizan Silva ${ }^{1}$, Ryo Matsumoto ${ }^{2}$, José Antonio Cupertino ${ }^{3}$, Luiz Alberto Santos ${ }^{1}$, Ana Carolina Ferreira Dominguez ${ }^{1}$ and Laisa da Fonseca Aguiar ${ }^{1},{ }^{1}$ Universidade Federal Fluminense, ${ }^{2}$ Meiji University, ${ }^{3}$ Pontifícia Universidade Católica do Rio Grande do Sul (PUCRS)

Copyright 2021, SBGf - Sociedade Brasileira de Geofísica

This paper was prepared for presentation during the $17^{\text {th }}$ International Congress of the Brazilian Geophysical Society held in Rio de Janeiro, Brazil, 16-19 August 2021.

Contents of this paper were reviewed by the Technical Committee of the $17^{\text {th }}$ International Congress of the Brazilian Geophysical Society and do not necessarily represent any position of the SBGf, its officers or members. Electronic reproduction or storage of any part of this paper for commercial purposes without the written consent of the Brazilian Geophysical Society is prohibited.

\section{Abstract}

This work aims to evaluate the best seismic attributes for identifying the BSRs of Umitaka Spur, a well-known gas hydrates field, from the Joetsu Basin, Japan. For this purpose, it uses 2D single-channel seismic data from Expeditions NT07-20 and NT08-09 made available by the Japan Agency for Marine-Earth Science and Technology (JAMSTEC). The methodology consisted of the analysis of six seismic attributes to highlight the Bottom Simulating Reflectors (BSRs), through Schlumberger's Petrel 2019 software. These attributes were Envelope, RMS Amplitude, Amplitude Volume Technique, Relative Acoustic Impedance, Spectral Decomposition and Instantaneous Frequency. Thus, this methodology was fundamental to reduce the ambiguities inherent to geophysics, by highlighting the real BSRs through the seismic assessment of more than one physical property (amplitude and frequency) and the geological attributes that highlighted the faults of the complex local geology.

\section{Introduction}

Investigating the presence of gas hydrates in the subsurface is important to mitigate geological hazards situations and to exploit this unconventional energy resource (Kvenvolden, 1993; Chong et al., 2016). The seismic reflection method is the most widely used geophysical method of exploration. For instance, in marine seismic profiles, the Bottom Simulating Reflector (BSR) is known to indirectly demarcate the Base of the Gas Hydrate Stability Zone (BGHSZ). It is a seismic reflector that is parallel and has a reverse polarity in relation to the seafloor reflector, which often crosscut the bedding plane of the host sediments (Buffett, 2000). However, identifying the true BSR can be difficult without the application of seismic attributes, because there may be cases of the occurrence of seismic reflectors similar to BSR, which do not mark BGHSZ. For instance, there are several studies that address the occurrence of more than one BSR (e.g., Posewang and Mienert, 1999; Foucher et al., 2002; Nakajima et al., 2014).
Seismic attributes are the main tools used to predict lithology of seismic reflection data, which can act as filters that quantify properties of seismic images (Taner, 2001). For instance, Aguiar et al. (2019) applied the Envelope attribute to highlight BSR in the Foz do Amazonas Basin, Brazil. Another examples, Santos et al. (2009) and de Oliveira (2009) used Spectral Decomposition to highlight anomalies associated with the accumulation of gas hydrates in Joetsu Basin, Japan and Pelotas Basin, Brazil, respectively.

Thus, this work aims to evaluate the best seismic attributes for identification of BSRs in a widely studied gas hydrates site, Umitaka Spur, Joetsu Basin, Japan (Figure 1). Hence, show which seismic attribute is useful to highlight the real BSR. For this purpose, were used the 2D post-stack seismic lines on time domain provided and already migrated by the JAMSTEC. These data are from Expeditions NT07-20 and NT08-09, carried out in 2007 and 2008 respectively.

According to Matsumoto et al., 2011, studies focusing on the origin and significance of shallow, massive to fracturefilling gas hydrates in Joetsu Basin have begun since 2004 by a research consortium of universities, national institutes and industries. Thus, miscellaneous studies involving gas hydrates issues in this area have been carried out, such as acoustic and seismic surveys (e.g., Saeki et al., 2009; Nakajima et al., 2014), geophysical (e.g., Santos et al., 2009), geochemical and geological analysis (e.g., Matsumoto et al., 2005, 2009, 2011, 2017; Freire et al., 2011; Snyder et al., 2020). The contribution this work is the knowledge of the effects of the application of six seismic attributes to enhance the BSRs and free gas zones in seismic profiles from this area, which is also useful for others areas of the world.

\section{Method}

The main steps of this work are summarize Figure 2. First, all of the 2D post-stack seismic lines on time domain were loaded into the Petrel 2019 software. Then, a quality control of these seismic profiles was carried out.

After that, the main step consisted of the application of six seismic attributes in Petrel. First, were applied the two seismic attributes that measure amplitude (Envelope and RMS Amplitude). Then, was applied the Amplitude Volume Technique (AVT), which consisted of applying a phase shift of $-90^{\circ}$ in RMS Amplitude seismic attribute. This technique is known as "TecVA" and was first proposed by Bulhões (1999) and then developed by Bulhões and de Amorim (2005). 


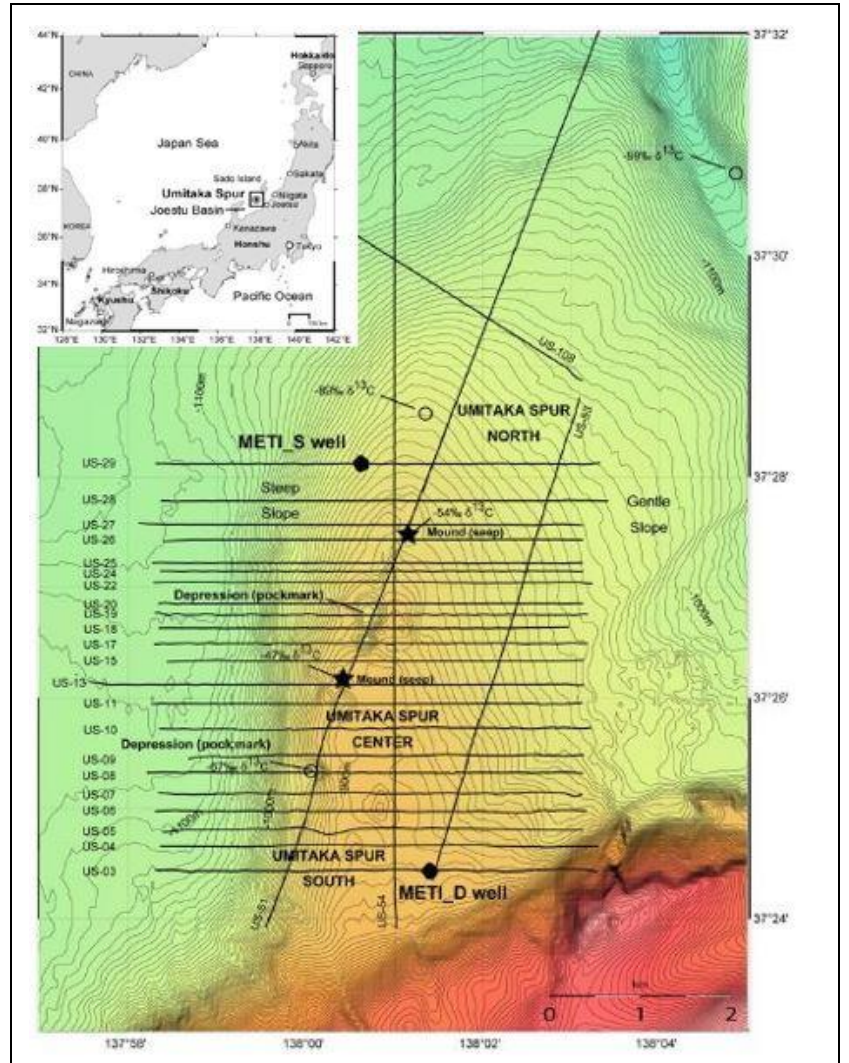

Figure 1 - Location map of the Joetsu Basin and Umitaka Spur. Map of the seafloor relief of the Umitaka Spur showing mounds and depressions in an NE-SW trend. Stars indicate seep locations. Open circles indicate carbon isotope analyses of sediments. The $2 D$ single channel seismic survey is shown (Freire et al., 2011).

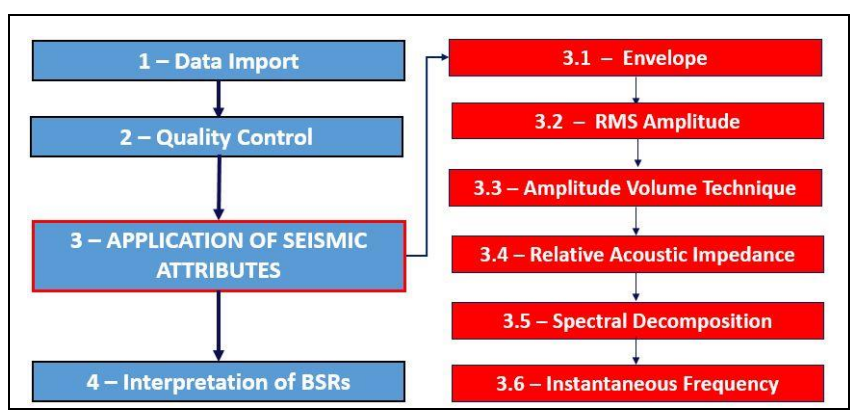

Figure 2 - Main work steps.

Then, the second geological attribute of this work, Relative Acoustic Impedance was used to highlight seismic reflectors. Ultimately, before applying the frequency attributes, an analysis of the frequency spectrum was made to obtain information on the frequency domain in each seismic profile. So, Spectral Decomposition and Instantaneous Frequency were applied.

Finally, the BSRs of each seismic profile were interpreted based on the analysis of these six seismic attributes applied.

\section{Results and Discussion}

First, all of the 2D post-stack seismic lines on time domain (SEG-Y format) provided by the JAMSTEC were loaded into the Petrel 2019 software. Then, a quality control of these seismic profiles was carried out, so only a seismic line was discarded because it was well curved, which was SP.2(4_FSP) from the NT07-20 Expedition.

Therefore, the seismic lines used in this work became twenty-eight in total. Then, a seafloor grid was done through the interpretations of the seafloor horizon of these seismic profiles.

After that, the application of seismic attributes to enhance BSRs on all seismic profiles began. However, due to the large number of seismic lines, only the results of the $S P .2\left(19 \_F S P\right)$ and SP.2(51-1_FSP) will be addressed here. They were chosen for this assessment because seismic section SP.2(19_FSP) shows a very visible pockmark (Figure 3) and SP.2(51-1_FSP) is a strike line (US-51 in Figure 1).

Note in Figure 3 that we have more than one reflector with a high negative amplitude and blanking zones in SP.2(19_FSP). From previous work, such as Freire et al., 2011, we know that the BSR is located approximately between 1.6 and $1.8 \mathrm{~s}$ TWT in the US-19 seismic section. However, if we did not have any prior information from the study area, note that it would be difficult to interpret where the true BSR would be, because it has more than one reflector close and parallel to the seabed with a strongly negative impedance contrast. So, applying seismic attributes is important to reduce these interpretation concerns.

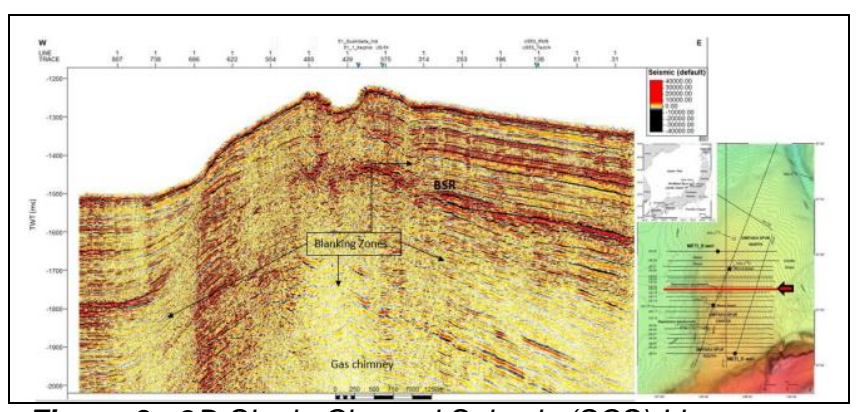

Figure 3 - 2D Single Channel Seismic (SCS) Line SP.2(19_FSP) from NT07-20 Expedition. The diffractions in the central part have not been fully collapsed in the seismic processing.

\section{Amplitude Envelope Analysis}

Before applying the Envelope, when doing an analysis of the amplitudes values extracted of the SP.2(19_FSP) SCS section, we can see that both the $\mathrm{H}$-II reflector and the BSR have strong negative amplitudes, contrasting with the positive reflection coefficient of the seafloor. 


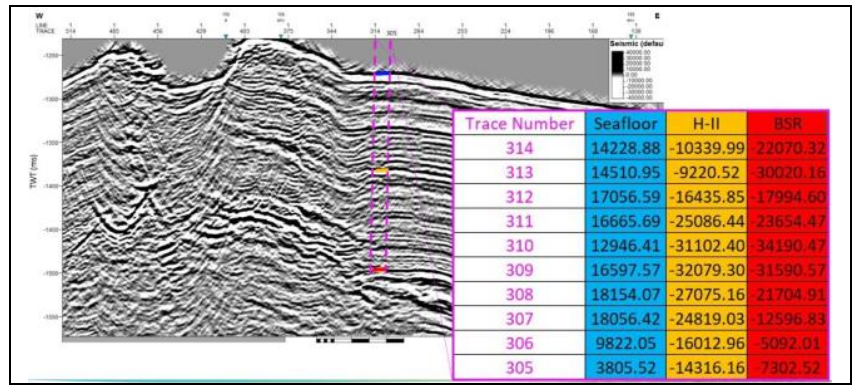

Figure $4-$ Zoom of the region of interest of the SP.2(19_FSP) with the amplitude values of stretches of the seabed, $\mathrm{H}-\mathrm{Il}$ and $\mathrm{BSR}$.

When applying the Envelope attribute, all values become positive (Figure 5). It measures total instantaneous energy (Taner et al., 1979). Note in figure 5 that all high acoustic impedance contrast were highlighted, such as the seismic reflectors $\mathrm{H}-\mathrm{I}$ and $\mathrm{H}-\mathrm{Il}$ of the Haizume Formation, BSR and the flat spot below it.

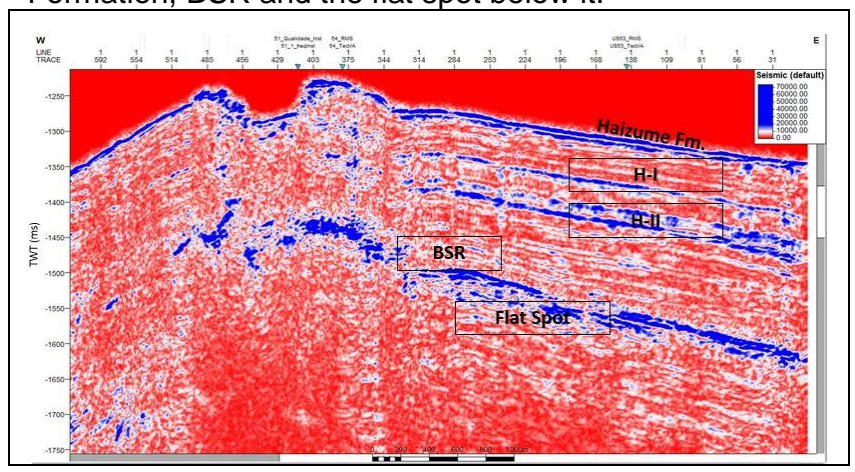

Figure 5 - SP.2(19_FSP) with Envelope Amplitude. Blue color highlights the greatest amplitudes while the red color corresponds to values close to zero.

However, it would not be possible to distinguish the true BSR from the $\mathrm{H}-\mathrm{Il}$ reflector just by analyzing this attribute. Thus, the envelope attribute is not so useful in distinguishing a true from a false BSR. Therefore, it is not recommended to use only this attribute to reach a final conclusion.

\section{RMS Amplitude and Amplitude Volume Technique}

The Amplitude Volume Technique (AVT) consisted of applying a phase shift of $-90^{\circ}$ in RMS Amplitude. Thus, before obtaining the result of the application of the AVT, we have the result of the RMS Amplitude. The RMS Amplitude highlighted extreme amplitude anomalies and it has an effect similar to the application of the envelope.

Then phase shift of $-90^{\circ}$ was applied (Figure 6). Note that it was useful to enhance the high impedance contrasts, discontinuities and so, the fault system. In addition, this created a pseudo-relief effect, thus highlighting the BSR.

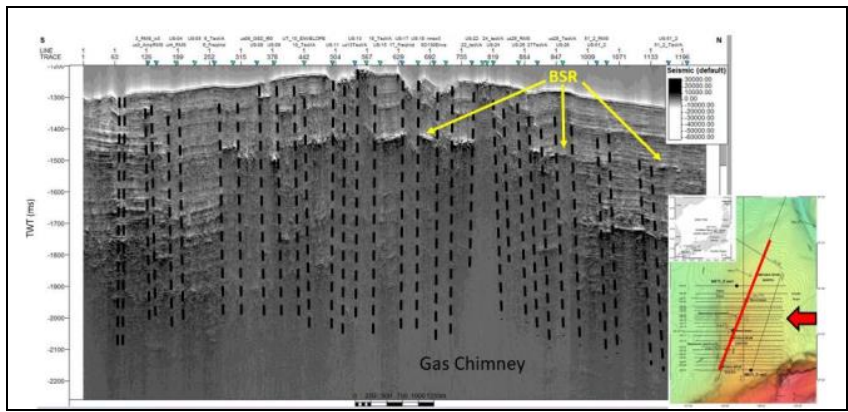

Figure 6 - Fault system interpreted with the application of Amplitude Volume Technique on the SP.2(51-1_FSP) seismic section.

\section{Relative Acoustic Impedance}

Comparing the result obtained (Figure 7) with Figure 3, it can be noted that RAl attribute highlighted all the seismic reflectors. Despite highlighting non-collapsed diffractions, there was an enhancement of the weak reflectors of the blanking zones, where there is presence of free gas. Note that the BSR appears much stronger than the $\mathrm{H}-\mathrm{I}$ and $\mathrm{H}-\mathrm{II}$ reflectors.

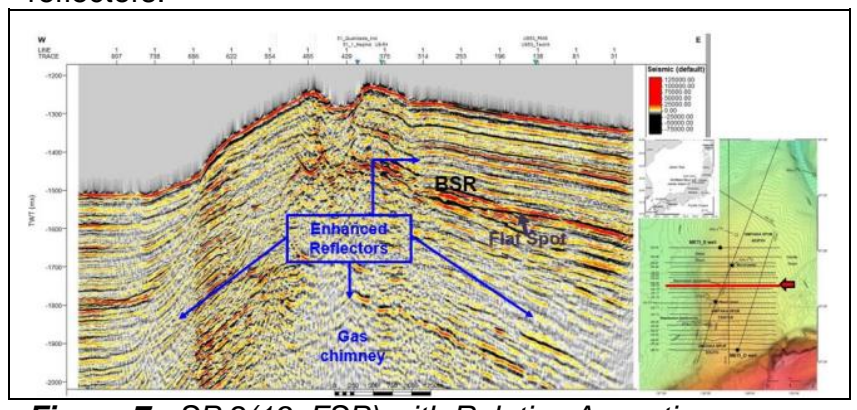

Figure 7 - SP.2(19_FSP) with Relative Acoustic Impedance. Arrows point to the highlighted reflectors of the blanking zones near the gas chimney and above the $B S R$.

\section{Spectral Decomposition}

Before applying the seismic frequency attributes, it is necessary to make an analysis of the most dominant frequencies in the area of interest of the seismic section to choose the central frequency of Spectral Decomposition. In this case, the most dominant frequencies were between $100 \mathrm{~Hz}$ and $80 \mathrm{~Hz}$.

Spectral Decomposition serves to highlight a certain frequency of the seismic data. For instance, a free gas zone attenuates the seismic signal. So, when using lower frequencies for spectral decomposition, it will highlight the free gas zones, as reported by de Oliveira (2009). Thus, to analyze the effects of different Spectral Decompositions, six different central frequencies were applied based on the dominant frequencies in the zone of interest. These frequencies were $25,50,75,100,125$ and $150 \mathrm{~Hz}$ (Figure 8). 


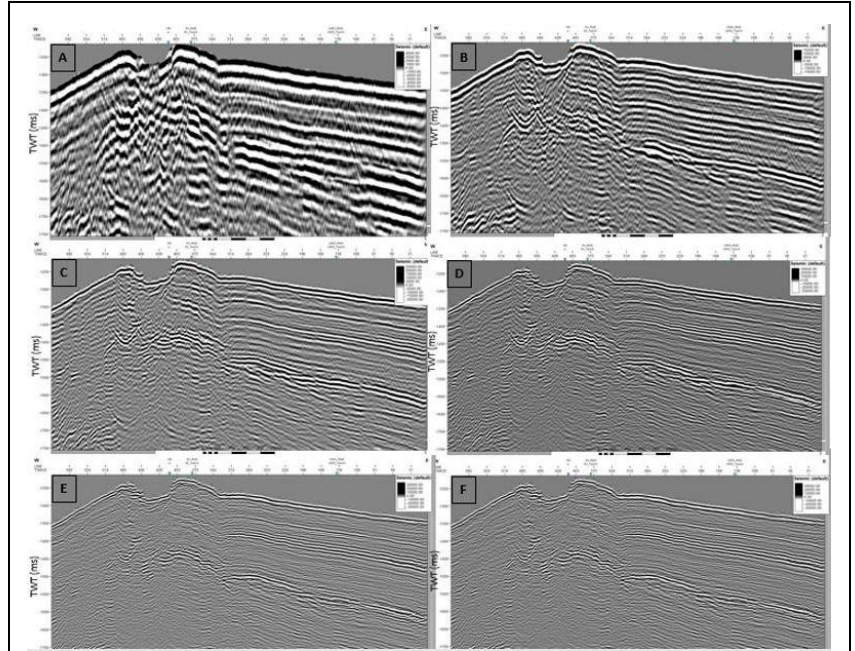

Figure 8 - Spectral Decomposition of SP.2(19_FSP) with (A) $25 \mathrm{~Hz}$; (B) $50 \mathrm{~Hz}$; (C) $75 \mathrm{~Hz}$; (D) $100 \mathrm{~Hz}$; (E) $125 \mathrm{~Hz}$ and (F) $150 \mathrm{~Hz}$.

Incredibly, all images are on the same scale (Figure 8, AF). Apparently, it seems that the image corresponding to the SD with a frequency of $25 \mathrm{~Hz}$ is with a greater zoom, because the seismic reflectors seem to be thicker. This is due to the tuning effect of thin bed interference. According to Laughlin et al. (2002) and de Oliveira (2009), in thin reservoirs a lower dominant frequency would highlight the thicker parts on an amplitude map and this is what happened when choosing a central frequency of $25 \mathrm{~Hz}$. While seismic data with a higher dominant frequency highlight the thinner parts of the reservoir on amplitude maps, as seen in Figure $8 \mathrm{E}-\mathrm{F}$. Thereby, from $\mathrm{A}$ to $\mathrm{F}$, we have the illusion that the scale is increasing, but in fact it is the same, what changed was the frequency parameters of the Spectral Decomposition.

After that, to highlight the energies, the envelope seismic attribute was applied to these seismic sections. Note that the spectral decomposition with a frequency of $25 \mathrm{~Hz}$ has red spots, below the pockmark and below the $\mathrm{H}-\mathrm{II}$ reflector. These spots correspond to greater attenuation of the seismic signal and are probably related to the presence of free gas.

Moreover, the most balanced result obtained for the interpretation of the reflectors was the frequency of 100 $\mathrm{Hz}$ (Figure $8 \mathrm{D}$ and Figure $9 \mathrm{D}$ ). This was to be expected, as the frequency analysis showed that $100 \mathrm{~Hz}$ was the most present frequency. However, it is observed that the distinction between the true BSR and the strong anomaly of the $\mathrm{H}$-II horizon can only be made due to knowledge of bibliographic references of the region. Thus, for a more detailed investigation of seismic attenuation, instantaneous frequency must be applied.

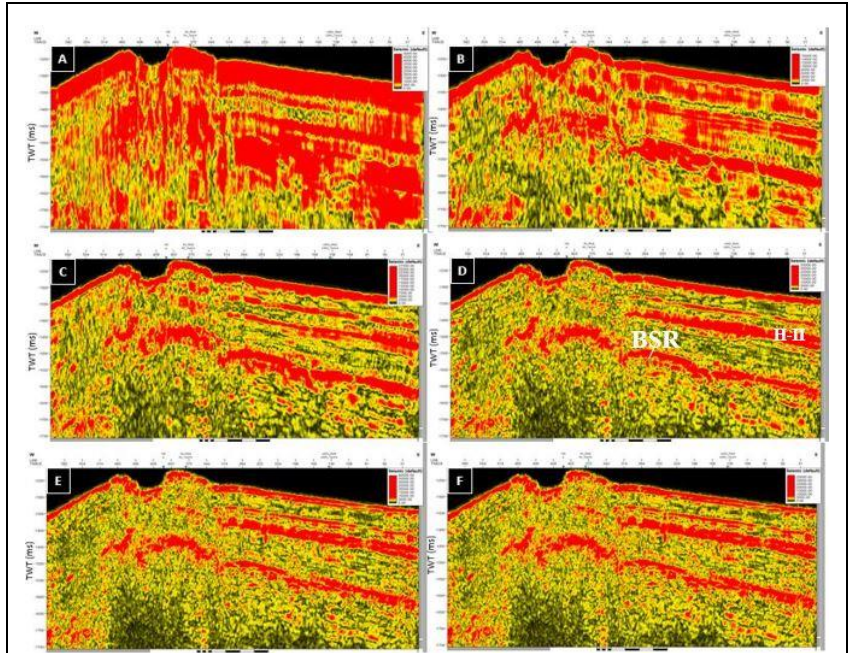

Figure 9 - Spectral Decomposition plus Envelope of SP.2(19_FSP) with (A) $25 \mathrm{~Hz}$; (B) $50 \mathrm{~Hz}$; (C) $75 \mathrm{~Hz}$; (D) $100 \mathrm{~Hz} ;(E) 125 \mathrm{~Hz}$ and (F) $150 \mathrm{~Hz}$.

\section{Instantaneous Frequency}

After applying Instantaneous Frequency seismic attribute, it is possible to notice that there is a greater dominance of the lower frequencies in the deeper areas (Figure 10). These red spots may occur due to the high flow of methane from deep sources (Figure 10). This interpretation can be made based on previous studies of geochemical analysis, where these gas chimneys are occasionally associated with seafloor methane seeps and gas plume (Matsumoto et al., 2005; Matsumoto et al., 2009). For instance, based on Freire et al. (2011) interpretation, we can relate the seismic attenuation in the seismic section SP.2(19_FSP) with the presence of gas, which migrates vertically through the faults and laterally through the carrier beds (Figure 10).

Besides that, note the red spots between $2.0 \mathrm{~s}$ and $2.4 \mathrm{~s}$ TWT. They correspond to the previous observed blanking zones (Figure 3). The high flow of methane from deep sources should attenuate the seismic signal causing this effect.

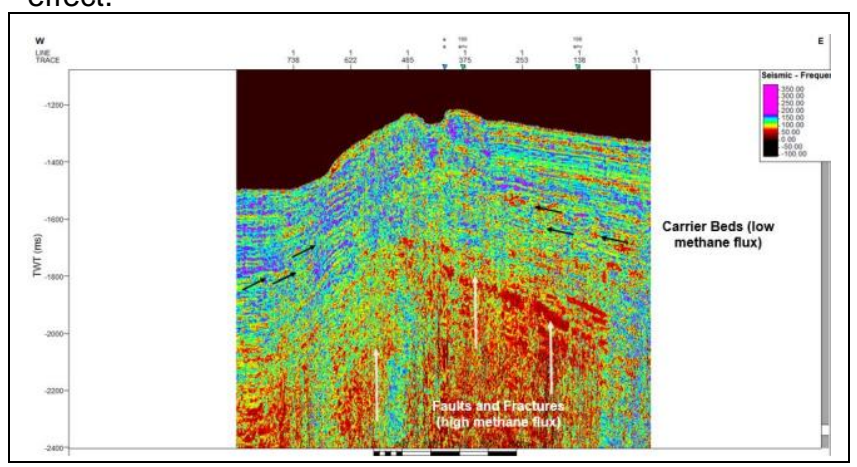

Figure 10 - SP.2(19_FSP) with Instantaneous Frequency seismic attribute. Red, yellow and green spots represent frequency values close to $0 \mathrm{~Hz}, 50 \mathrm{~Hz}$ and $100 \mathrm{~Hz}$, respectively. While purple spots represent frequency values approximately greater than $175 \mathrm{~Hz}$ (higher frequency values). Black arrows correspond to the low 
methane flux through carrier beds while white arrows high methane flux from deep sources through faults.

In addition, blue and purple spots represent regions with less seismic attenuation. So, since the gas hydrates only exist in the Gas Hydrate Stability Zone (GHSZ), only the purple and blue spots above the BSR, less than $1.6 \mathrm{~s}$ TWT, could mean their presence in the sediments. While the other purple and blue zones below the BSR should represent more compacted sediments.

Thereby, considering these observations and zooming in on the shallow central part, the interpretations of Figure 11 can be made. Note that gas hydrates should serve as a seal for the methane flux.

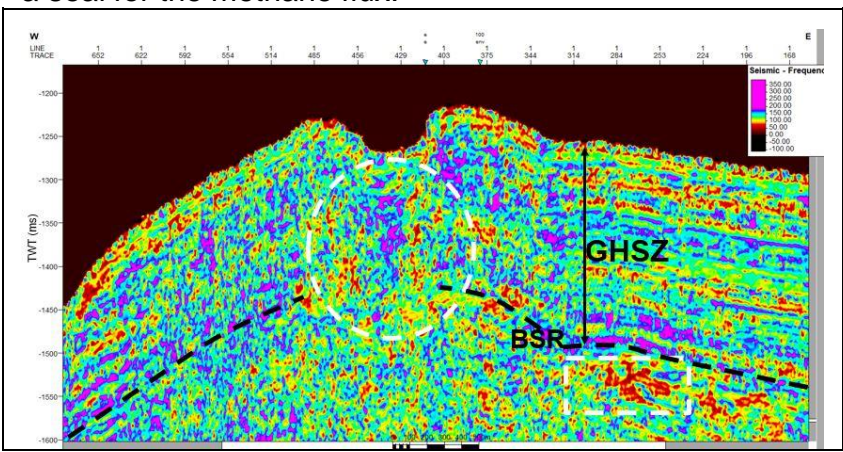

Figure 11 - SP.2(19_FSP) with Instantaneous Frequency seismic attribute. Black, red, yellow and green spots represent frequency values close to $0 \mathrm{~Hz}, 50 \mathrm{~Hz}, 100 \mathrm{~Hz}$ and $125 \mathrm{~Hz}$ respectively. While purple spots represent frequency values approximately greater than $175 \mathrm{~Hz}$ (higher frequency values). White rectangle highlights a greater seismic attenuation below the BSR, while white circle highlights possible presence of gas hydrates (purple spot) with free gas (red spots) below the pockmark.

Moreover, note the greater seismic attenuation probably generated by the presence of gas concentration in gas chimney structures above BSR (red and yellow spots in Figure 11). This result matches unusual low acoustic velocities observed above BSR in previous work. For instance, Saeki et al. (2009) through a velocity analysis of 3D seismic survey data reported anomalously low velocities (1200-1300 m/s) above the BSR horizon, possible affected by the presence of free gas bubbles (Matsumoto et al., 2009, 2011; Freire, 2011). These low velocities were also observed by Log-While-Drilling (LWD) data from the work of Matsumoto et al. (2017). Thus, purple spot within red spots below the pockmark and above the BSR implies that free gas is stable well within the gas hydrate stability zone (GHSZ), as observed by Matsumoto et al. (2011).

Furthermore, when comparing figure 4 with figure 11, it becomes even more evident that the reflector $\mathrm{H}-\mathrm{Il}$ is not a BSR. In figure 11, it can be seen that below the BSR, the white rectangle highlights the strong seismic attenuation caused by the free gas zone. While above the BSR (purple spot) the seismic attenuation is less, probably due to the presence of gas hydrates.

Final Interpretation of BSRs
After analyzing these six seismic attributes applied to each seismic section, the BSR of each seismic profile was interpreted. Therefore, Figure 12 illustrates these twenty-eight interpreted BSRs.

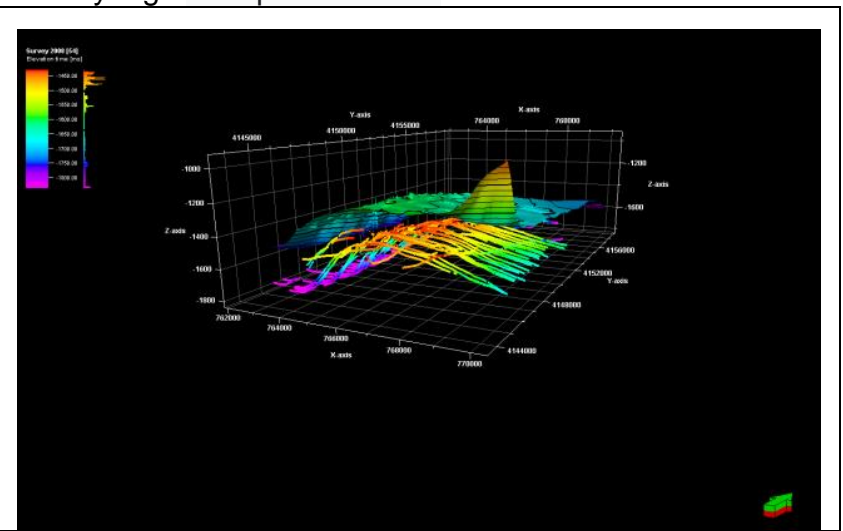

Figure 12 - Interpreted BSRs for each seismic section below the seafloor grid. The data is in milliseconds. The color scale refers to the Elevation time (ms) of the BSRs. Thus, the longer the time, the greater the depth. Red colors correspond to shallow areas (close to $1.4 \mathrm{~s}$ TWT), while purple colors represent deeper zones (1.8 s TWT). "Survey 2008 [54]" to the right of the color scale shows the values of elevation time $(\mathrm{ms})$ of the BSR from SP.1(ut-54) strike seismic line from NT08-09 Expedition.

When analyzing the interpreted BSRs, it can be seen that the shallow stretches of BSRs in red are associated with gas chimneys (Figure 12), where the upward migration of hydrocarbon gases develops gas hydrates accumulations. These zones are also associated with occurrence of mounds and pockmarks (Figure 1), as noted in previous work (e.g., Matsumoto et al. 2009, 2011, 2017; Freire et al., 2011, Snyder et al. 2020).

Thereby, the BSRs in gas chimneys ranges from 1.4 to 1.5 seconds two way time (about 0.1 TWT below seafloor), while in the surrounding sediments, the depth ranges from 1.6 to 1.8 seconds TWT (about 0.3 TWT bsf).

\section{Conclusions}

This work consisted of the application and analysis of seismic attributes to identify the Bottom Simulating Reflectors (BSRs) in the Umitaka Spur gas hydrate province, Joetsu Basin, Japan. Thus, six seismic attributes were applied to twenty-eight single-channel 2D seismic profiles using Petrel 2019 software.

The Envelope seismic attribute served to highlight the regions of greatest amplitude energy. However, it proved ineffective to distinguish a true BSR from another reflector with high impedance contrast. RMS Amplitude generated a result similar to the Envelope, but this attribute was used mainly to apply the Amplitude Volume Technique (AVT).

Both the AVT seismic attribute and the Relative Acoustic Impedance served to highlight the impedance contrasts of the layers and thus the discontinuities, allowing a better visualization of the geological faults of the seismic sections. The RAI attribute made reflectors stronger, 
thereby reducing the effects of acoustic transparency of free gas zones.

Ultimately, the Spectral Decomposition and Instantaneous Frequency were useful to highlight the BSR, which comparatively is like a seismic interface that separates a zone of greater seismic attenuation (free gas zone below) from a milder seismic attenuation (gas hydrates in sediments above). Thus, these seismic attributes were relevant to reduce the ambiguities of the attributes that measure only amplitude.

Therefore, seismic attributes play a fundamental role in the analysis of subsurface layers. Their combination gives security to the interpreter when analyzing similar results of each one. Thus, the true BSR has been interpreted and this work reaffirmed the unusual presence of free gas above the BSR as reported by other studies in this region.

\section{Acknowledgments}

The authors are thankful to Japan Agency for MarineEarth Science and Technology (JAMSTEC) for providing data from NT07-20 and NT08-09 Expeditions.

\section{References}

AGUIAR, L. et al. Analysis of seismic attributes to recognize bottom simulating reflectors in the Foz do Amazonas basin, Northern Brazil. Brazilian Journal of Geophysics, v. 37, n. 1, p. 43-53, 2019.

BUFFETT, B. A. Clathrate hydrates. Annual Review of Earth and Planetary Sciences, v. 28, n. 1, p. 477-507, 2000.

BULHÕES, É. M. Técnica "VOLUME DE AMPLITUDE" para mapeamento de feições estruturais. In: 6th International Congress of the Brazilian Geophysical Society. European Association of Geoscientists \& Engineers, 1999. p. cp-215-00239.

BULHÕES, É. M.; DE AMORIM, W. N. Princípio da SismoCamada Elementar e sua aplicação à Técnica Volume de Amplitudes (tecVA). In: 9th International Congress of the Brazilian Geophysical Society. European Association of Geoscientists \& Engineers, 2005. p. cp-160-00352.

CHONG, Z. et al. Review of natural gas hydrates as an energy resource: Prospects and challenges. Applied energy, v. 162, p. 1633-1652, 2016.

DE OLIVEIRA, O. Decomposição espectral de dados sísmicos usando a transformada de wavelet: aplicação no estudo das acumulações de hidratos de gás na bacia de Pelotas. Dissertação (Mestrado em Engenharia de Reservatório e de Exploração de Petróleo) - Universidade Estadual do Norte Fluminense. Macaé, RJ, p. 60. 2009.

FREIRE, A. F. M.; MATSUMOTO, R.; SANTOS, L. A. Structural-stratigraphic control on the Umitaka Spur gas hydrates of Joetsu Basin in the eastern margin of Japan Sea. Marine and Petroleum Geology, v. 28, n. 10, p. 1967-1978, 2011
FOUCHER, J. ; NOUZÉ, H.; HENRY, P. Observation and tentative interpretation of a double BSR on the Nankai slope. Marine Geology, v. 187, n. 1-2, p. 161-175, 2002.

KVENVOLDEN, K. A. Gas hydrates-geological perspective and global change. Reviews of geophysics, v. 31, n. 2, p. 173-187, 1993.

LAUGHLIN, K.; GAROSSINO, P.; PARTYKA, G. Spectral decomposition applied to 3D. AAPG Explorer, v. 23, n. 5, p. 28-31, 2002.

MATSUMOTO, R. et al. Formation and collapse of gas hydrate deposits in high methane flux area of the Joetsu Basin, eastern margin of Japan Sea. JOURNAL OF GEOGRAPHY-CHIGAKU ZASSHI, v. 118, n. 1, p. 43-71, 2009.

MATSUMOTO, R. et al. Methane plumes over a marine gas hydrate system in the eastern margin of Japan Sea: A possible mechanism for the transportation of subsurface methane to shallow waters. In Proceedings of the 5th International Conference on Gas Hydrates, Vol. 3, pp. 749-754, 2005.

MATSUMOTO, R. et al. Occurrence and exploration of gas hydrate in the marginal seas and continental margin of the Asia and Oceania region. Marine and Petroleum Geology, v. 28, n. 10, p. 1751-1767, 2011.

MATSUMOTO, R. et al. Occurrence and Origin of thick deposits of massive gas hydrates, eastern margin of the Sea of Japan Sea. . In Proceedings of the 9th International Conference on Gas Hydrates, 2017.

NAKAJIMA, T. et al. Formation of pockmarks and submarine canyons associated with dissociation of gas hydrates on the Joetsu Knoll, eastern margin of the Sea of Japan. Journal of Asian Earth Sciences, v. 90, p. 228-242, 2014.

POSEWANG, J.; MIENERT, J. The enigma of double BSRs: indicators for changes in the hydrate stability field?. Geo-marine letters, v. 19, n. 1-2, p. 157-163, 1999.

SAEKI, Tatsuo et al. 3D seismic velocity structure below mounds and pockmarks in the deep water southwest of the Sado Island. In: AGU Fall Meeting Abstracts. 2009. p. OS43C-02.

SANTOS, L. A.; FREIRE, A. F. M. ; MATSUMOTO, R. Q estimation in hydrate bearing sediments at Joetsu KnollJapan Sea. In: 11th International Congress of the Brazilian Geophysical Society. European Association of Geoscientists \& Engineers, 2009. p. cp-195-00261.

SNYDER, G. T. et al. Magmatic fluids play a role in the development of active gas chimneys and massive gas hydrates in the Japan Sea. Chemical Geology, v. 535, p. $119462,2020$.

TANER, M. T. Seismic attributes: Canadian Society of Exploration Geophysicists Recorder. 2001.

TANER, M. T.; KOEHLER, F.; SHERIFF, R. E. Complex seismic trace analysis. Geophysics, v. 44, n. 6 , p. 10411063, 1979. 